\title{
Pectenotoxin's ABCDE-ring system: A complex target to test the potential of singlet oxygen super cascades as tools for synthesis
}

\author{
Antonia Kouridaki, ${ }^{[a]}$ Manolis Sofiadis,${ }^{[a]}$ Tamsyn Montagnon ${ }^{[a]}$ and Georgios Vassilikogiannakis ${ }^{*[a]}$ \\ Dedication ((optional))
}

\begin{abstract}
A difuran substrate is synthesized which then participates in a singlet oxygen-mediated super cascade reaction sequence that gives the $A B C D E-$ ring skeleton of certain pectenotoxins. During this super cascade, two separate reaction sequences occur in parallel to create both the [6,6]-spiroketal and the 2,8-dioxabicyclo[3.2.1]octane motif, in one synthetic operation.
\end{abstract}

\section{Introduction}

The pectenotoxins (PTXs, Figure 1) are a family of macrolide natural products produced by dinoflagellates (Dinophysis fortii) and found worldwide. Members of the family were first isolated from the host shellfish (a scallop named, Patinopecten yessoensis) by Yasumoto et al. in the late 1980s. ${ }^{[1]}$ Their potentially useful cytotoxicity ${ }^{[2]}$ thought to be the result of a novel mode of F-actin disruption, as well as, their challenging structures have ensured that this family of molecules continues to receive considerable attention.

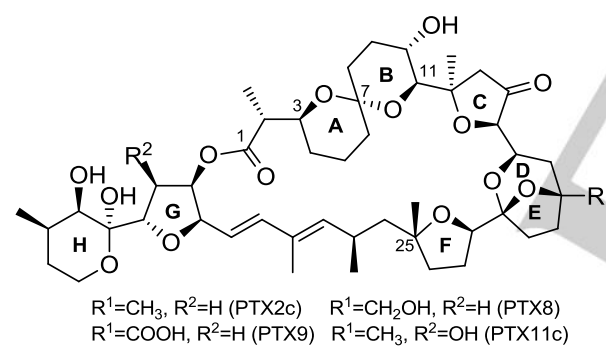

Figure 1. Structures of PTXs 2c, 8, 9 and 11c.

When scarce natural products show a novel mode of activity against a range of cancer cell lines, such as is the case here ${ }^{[2]}$ efficient syntheses become all the more important in order to establish a supply of compounds for further exploration and testing. Synthetically, the PTXs' significant challenges arise from the oxygen-rich and stereochemically-complex nature of the molecules, as well as, from the contiguous series of cyclic units that stretches all the way from C3 to C25. This section contains six different rings in the form of a $[6,6]$-spiroketal, two 5 membered rings with quaternary junctions and a 2,8dioxabicyclo[3.2.1]octane motif.

[a] A. Kouridaki, M. Sofiadis, T. Montagnon, G. Vassilikogiannakis Department of Chemistry University of Crete

Vasilika Vouton, Iraklion, Crete, Greece

E-mail: vasil@chemistry.uoc.gr

http://www.chemistry.uoc.gr/vassilikogiannakis/

Supporting information for this article is given via a link at the end of the document.
PTXs 4 and 8 were successfully synthesized in 2002 by Evans and coworkers. ${ }^{[3]}$ Very recently, a total synthesis of PTX 2 has also been achieved by Fujiwara et al. ${ }^{[4]}$ In addition to these complete works, substantial advances towards various fragments (within the A to F-ring section of the pectenotoxins) have been made by a number of other groups. ${ }^{[5]}$ Our goal was a little different; we sought to use this complex and synthetically challenging structure as the testing ground to prove that nonclassical strategies which employ singlet oxygen have significant potential in synthesis and are not just limited to simple examples or situations. The investigation would seek to verify whether singlet oxygen could be used to stitch up an extended polyfunctionalised molecule to yield a much larger and more architecturally intricate framework than had ever been targeted previously using such chemistry. ${ }^{[6],[7]}$ More specifically, it was hoped that singlet oxygen could be used to initiate a double cascade reaction sequence that would furnish the pectenotoxin $A B C D E$-ring fragment from a difuran precursor in one synthetic operation (Scheme 1).

The advantages associated with the success of such an approach are many. Polyoxygenated molecules offer a tough testing ground for those seeking to develop greener and more sustainable chemical methods. In the synthesis of these molecules it is inherently difficult to avoid the repeated use of protecting groups, ${ }^{[8]}$ or to promote redox-economy,${ }^{[9]}$ because of the reactivity of the carbon-oxygen-based functionalities. It requires a rare thing, an oxidant that reacts very controllably and selectively, like singlet oxygen. Singlet oxygen's advantages don't end here; it is generated from air, produces no waste (toxic or otherwise), it is atom-economic, and, by facilitating cascade reaction sequences, it promotes exceptional levels of stepeconomy ${ }^{[6]}$ Indeed, singlet oxygen would appear to fit very well into the paradigms of ideal synthesis ${ }^{[10]}$ and sustainability.

Herein, we present the results of the investigation in which a singlet oxygen super cascade has been targeted. A singlet oxygen super cascade is defined as two singlet oxygenfacilitated cascade reaction sequences occurring in parallel. In this case, it was hoped that the [6,6]-spirocyclic unit and the 2,8 dioxabicyclo[3.2.1]octane unit could be constructed in one synthetic operation. Previously, some precedent had been separately attained for each of the desired cascade sequences using simpler substrates and run independently from each other, not in parallel..$^{7 b, c, e]}$ The product, in this case, would be by far the most three-dimensionally complex fragment to be made to-date using a singlet oxygen-facilitated cascade reaction sequence. It is of note that the proposed starting substrate 1a (Scheme 1) contains five different hydroxyl groups, none of which is protected. It was hoped that four of them would participate in the two parallel cascade reaction sequences and one would remain unaltered throughout the oxidative reaction sequence. Scheme 1 describes, using a mechanistic format, what we were hoping to achieve with the super cascade reaction sequence. 
<smiles>Cc1ccc(CC[C@](C)(O)C[C@H](O)[C@H]2OC(C)([C@H](O)c3ccc(CCCCO)o3)C[C@H]2O)o1</smiles>

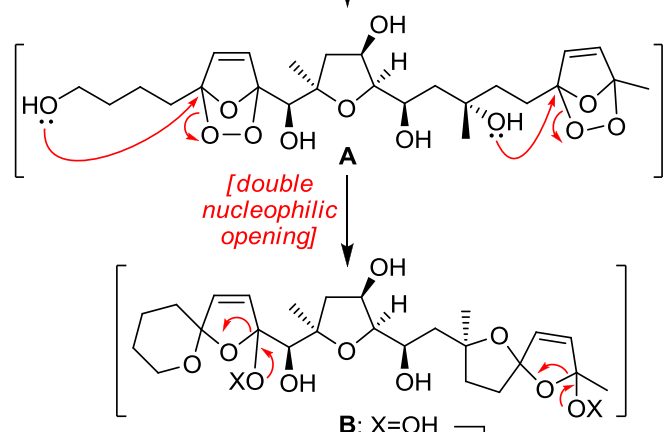

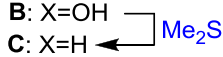

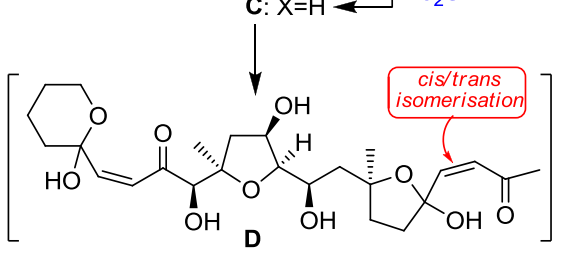
\begin{tabular}{c|c} 
[double \\
ketalisation]
\end{tabular} \mid acid

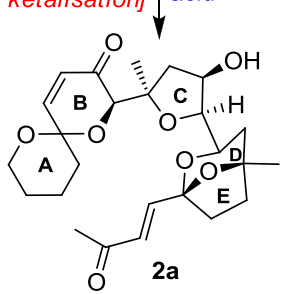

Scheme 1. Mechanism for the proposed super cascade reaction sequence.

\section{Results and Discussion}

The first task in this investigation was to synthesize substrate 1a. A workable synthesis for the C-ring and its subsequent attachment to an appropriately substituted furan precursor of the DE-ring motif, to give fragment 3 (Scheme 2), had been deconvoluted previously. ${ }^{[7]}$ The route we chose to employ from this point onwards was dictated by the acute difficulties encountered in differentiating between the secondary alcohol at $\mathrm{C} 14$ and the hindered neo-pentyl alcohol at C11 (pectenotoxin numbering, Scheme 2). Numerous reactions (deprotections, protections and oxidations) attempted on a series of related compounds failed to afford any progress because they all occurred with very similar rates at both these positions. To solve this conundrum, the 1,3-relationship between the hydroxyl groups appended to $\mathrm{C} 14$ and $\mathrm{C} 16$ was exploited. Thus, a double deprotection of substrate $\mathbf{3}$ was undertaken using TBAF to afford tetraol 4 (96\% yield). Acetal $\mathbf{5}$ was then synthesized using standard acetal-formation conditions (2,2dimethoxypropane, $p-\mathrm{TsOH}$, yield $96 \%$ ). Oxidation of the

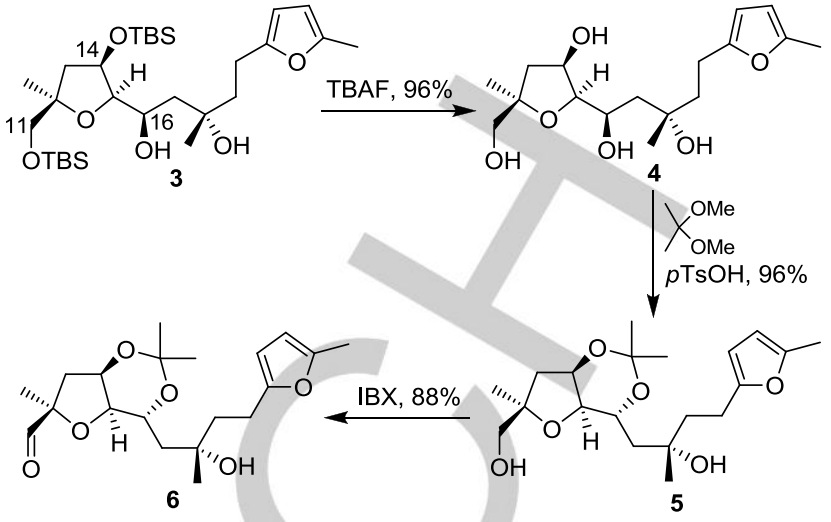

Scheme 2. Synthesis of key aldehyde 6 .

remaining primary alcohol (at $\mathrm{C} 11$ ) was then achieved with IBX to afford aldehyde 6 in $88 \%$ yield. It is of note that when undertaken in DMSO (classical protocol) this reaction was extremely slow requiring overnight; however, when the DMSO was replaced with DMF the reaction rate accelerated significantly and similar conversion could be attained in just $3 \mathrm{~h}$. DMF may be acting here as an activating ligand for IBX in line with previous observations relating to IBX's reactivity in the presence of different donor ligands. ${ }^{[11]}$
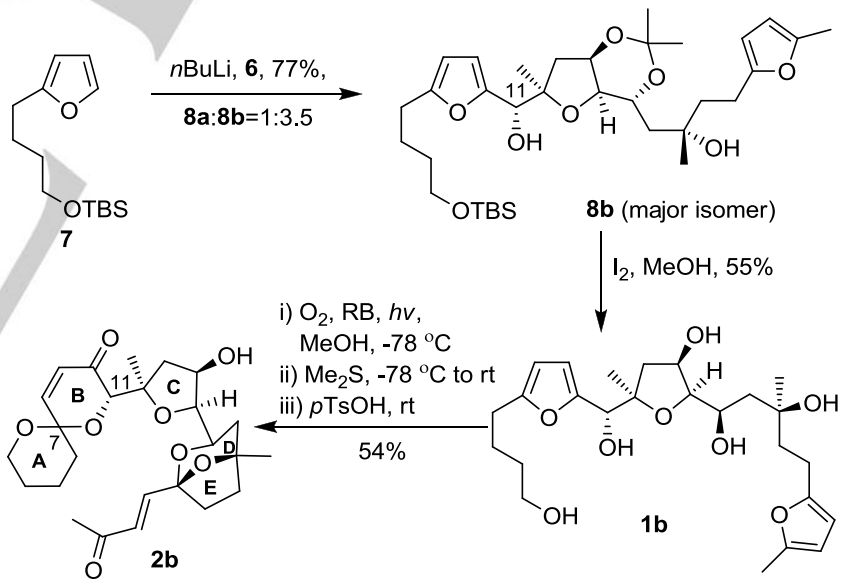

Scheme 3. Synthesis of substrate $\mathbf{1 b}$ and its photooxygenation.

Aldehyde 6 was now ready to serve as the electrophile that would react with the furyl anion formed by deprotonation of furan 7 with $n \mathrm{BuLi}$ (Scheme 3). Thus, difuran 8 was obtained with a yield of $77 \%$ and as a $1: 3.5$ mixture of diastereoisomers (8a:8b). These diastereoisomers proved to be very difficult to separate. Sufficient amounts of the major isomer (8b) could be isolated from the mixture to continue with the synthesis and to confirm the stereochemistry of this diastereoisomer. Diastereoisomer $\mathbf{8 b}$ was proven, by synthesis of its methoxyphenylacetic (MPA) esters, to have the $(S)$-configuration at the newly formed stereocentre (C11 pectenotoxin numbering). ${ }^{[12]}$ Since, this diastereoisomer (8b) was not the desired one, attempts were 
made (including acid catalysed epimerization, oxidationreduction protocols and a Mitsunobu inversion) to invert the configuration at $\mathrm{C} 11$, both at this stage, and, within several other closely related compounds. These attempts were not successful due in large part to the extremely hindered environment around C11, and it was, therefore, decided to proceed with the testing of the ambitious singlet oxygen-initiated super cascade sequence using diastereoisomer $\mathbf{8 b}$. To avoid decomposition, it was found that it was necessary to use iodine in methanol to effect concomitant deprotection of the TBS-ether and the acetal of $\mathbf{8 b}$. Using these conditions sensitive difuran $\mathbf{1 b}$, which has five free hydroxyl groups, could be obtained. The scene was now set to test the super cascade. To this end, a solution of difuran $\mathbf{1 b}$ and catalytic rose Bengal (RB, $3 \times 10^{-4} \mathrm{M}$ ) in $\mathrm{MeOH}$ was cooled to $78{ }^{\circ} \mathrm{C}$ and subjected to standard photooxygenation conditions: namely, irradiation with visible spectrum light for 6 mins whilst oxygen was bubbled through the solution. An excess of dimethylsulphide was then added at $-78{ }^{\circ} \mathrm{C}$ to affect the reduction of the bis-hydroperoxide intermediate (type $\mathbf{B}$, Scheme 1). Low temperature reaction conditions were used in order to suppress a competing fragmentation reaction $;^{[13]}$ namely, the known fragmentation of 2-( $\alpha$-hydroxyalkyl) furans to give the corresponding 4-hydroxybutenolides. ${ }^{[13 a]}$ Finally, $p \mathrm{TsOH}$ (1 eq.) was added to aid the ring opening and ketalisation steps of the cascade (type $\mathbf{C} \rightarrow \mathbf{D} \rightarrow \mathbf{2 a}$, Scheme 1). The product of this one pot cascade reaction sequence was the expected pentacycle $\mathbf{2} \mathbf{b}$ isolated in $54 \%$ yield as a mixture of 2 diastereoisomers at C7 in $5: 1$ ratio. The $\mathrm{C} 7$ centre is readily epimerisable and its configuration changes from substrate to substrate, as evidenced by previous syntheses. ${ }^{[3]-[5]}$ The structure and stereochemistry of the product $\mathbf{2 b}$ were confirmed by undertaking a series of ${ }^{1} \mathrm{H}$ COSY, HMBC, HSQC, NOESY and NOE experiments. Thus, the ambitious super cascade had worked and the product it produced $(\mathbf{2 b})$ represents the ABCDE-ring skeleton of the pectenotoxins albeit with the incorrect stereochemistry at $\mathrm{C} 11$; a fault introduced by limitations to classical chemistry earlier in the substrate synthesis, not by the highly effective super cascade.

\section{Conclusions}

A super cascade reaction sequence has been developed during which two separate singlet oxygen-initiated sequences are run in parallel. In this cascade a flatter difuran substrate $\mathbf{1 b}$ is oxidized and stitched up to yield a three dimensionally complex pentacyclic product $\mathbf{2} \mathbf{b}$. This super cascade shows the power of singlet oxygen to orchestrate the rapid and highly effective construction of complex architectures. The substrate for the super cascade sequence contains five unprotected hydroxyl groups all of which behaved as desired during the cascade reaction sequence. The reaction sequence produces both a [6,6]-spiroketal unit and a 2,8-dioxabicyclo[3.2.1]octane motif showing that the kind of structures exhibited by complex polyoxygenated polycyclic natural products, such as the pectenotoxins, are not beyond the reach of this non-classical sustainable chemistry.

\section{Experimental Section}

Pentacycle 2b: A solution of difuran 1b (15 mg, $0.032 \mathrm{mmol})$ in $\mathrm{MeOH}$ $(2.5 \mathrm{~mL})$ containing rose Bengal $\left(3 \times 10^{-4} \mathrm{M}\right)$ as a photosensitiser, was placed in a test tube and cooled to $-78^{\circ} \mathrm{C}$. Oxygen was gently bubbled through the solution while it was irradiated with a xenon Variac Eimac Cermax $300 \mathrm{~W}$ lamp for $6 \mathrm{mins}$, at the same low temperature. An excess of $\mathrm{Me}_{2} \mathrm{~S}(23 \mu \mathrm{L}, 0.33 \mathrm{mmol})$ was added to the crude mixture at $-78^{\circ} \mathrm{C}$. The solution was then warmed to r.t. and stirred for $4 \mathrm{~h}$ after which time it was concentrated in vacuo. The residue was then diluted with $\mathrm{CH}_{2} \mathrm{Cl}_{2}(1$ $\mathrm{mL}), p \mathrm{TsOH} \cdot \mathrm{H}_{2} \mathrm{O}(6 \mathrm{mg}, 0.031 \mathrm{mmol})$ was added and the stirring was continued for a further $1 \mathrm{~h}$ at the same temperature. The reaction mixture was washed with saturated aq. $\mathrm{NaHCO}_{3}(0.3 \mathrm{~mL})$. The layers were separated and the organic phase was dried $\left(\mathrm{MgSO}_{4}\right)$ and concentrated in vacuo. The desired product $\mathbf{2 b}(8 \mathrm{mg}, 54 \%)$ was isolated as a white solid by flash column chromatography (hexane: $\mathrm{Et}_{2} \mathrm{O}=2: 1 \rightarrow 100 \% \mathrm{Et}_{2} \mathrm{O}$ ).

\section{Acknowledgements}

The research leading to these results has received funding from the European Research Council under the European Union's Seventh Framework Programme (FP7/2007-2013)/ERC Grant Agreement No. 277588.

Keywords: singlet oxygen • furan • photooxygenation • pectenotoxin $\cdot$ cascade

[1] a) T. Yasumoto, M. Murata, Y. Oshima, M. Sano, G. K. Matsumoto, J. Clardy, Tetrahedron 1985, 41, 1019-1025; b) J.-S. Lee, T. Igarashi, S. Fraga, E. Dahl, P. Hovgaard, T. Yasumoto, J. Appl. Phycol. 1989, 1, 147-152.

[2] a) J. H. Jung, C. J. Sim, C.-O. Lee, J. Nat. Prod. 1995, 58, 1722-1726; b) I. Spector, F. Braet, N. R. Shochet, M. R. Bubb, Microsc. Res. Tech. 1999, 47, 18-37; c) F. Leira, A. G. Cabado, M. R. Vieytes, Y. Roman, A Alfonso, L. M. Botana, T. Yasumoto, C. Malaguti, G. P. Rossini, Biochem. Pharmacol. 2002, 63, 1979-1988; d) I. R. Ares, M. C. Louzao, M. R. Vieytes, T. Yasumoto, L. M. Botana, J. Exp. Biol. 2005, 208, 4345-4354; e) H.-D. Chae, T.-S. Choi, B.-M. Kim, J. H. Jung, Y.-J. Bang, D. Y. Shin, Oncogene 2005, 24, 4813-4819; f) J. S. Allingham, C. O. Miles, I. Rayment, J. Mol. Biol. 2007, 371, 959-970; g) B. Espiña, J. A. Rubiolo, FEBS J. 2008, 275, 6082-6088; h) B. Espiña, M. C. Louzao, I. R. Ares, E. S. Fonfría, N. Vilariño, M. R. Vieytes, T. Yasumoto, L. M. Botana, Chem. Res. Toxicol. 2010, 23, 504-515; i) S. C. Butler, C. O. Miles, A. Karim, M. J. Twiner, Tox. In Vitro 2012, 26, 493-499.

[3] a) D. A. Evans, H. A. Rajapakse, D. Stenkamp, Angew. Chem. Int. Ed. 2002, 41, 4569 - 4573; b) D. A. Evans, H. A. Rajapakse, A. Chiu, D. Stenkamp, Angew. Chem. Int. Ed. 2002, 41, 4573 - 4576.

[4] K. Fujiwara, Y. Suzuki, N. Koseki, Y.-I. Aki, Y. Kikuchi, S.-I. Murata, F. Yamamoto, M. Kawamura, T. Norikura, H. Matsue, A. Murai, R Katoono, H. Kawai, T. Suzuki, Angew. Chem. Int. Ed. 2014, 53, 780784.

[5] For a review of synthetic studies towards the PTXs up to 2006, see; a) R. Halim, M. A. Brimble, Org. Biomol. Chem. 2006, 4, 4048-4058; For some representative synthetic studies post-2006 of fragments within the A to F-ring section of the PTXs, see; b) D. Vellucci, S. D. Rychnovsky, Org. Lett. 2007, 9, 711-714; c) S. D. Lotesta, Y. Hou, L. J. Williams, Org. Lett. 2007, 9, 869-872; d) J. E. Aho, E. Salomäki, K. Rissanen, P. M. Pihko, Org. Lett. 2008, 10, 4179-4182; e) H. Helmboldt, J. E. Aho, P. M. Pinko, Org. Lett. 2008, 10, 4183-4185; f) S. Carley, M. A. Brimble, Org. Lett. 2009, 11, 563-566; g) S. Joyasawal, S. D. Lotesta, N. G. Akhmedov, L. J. Williams, Org. Lett. 2010, 12, 988-991; h) J. E. Aho, A. Piisola, K. S. Krishnan, P. M. Pihko, Eur. J. Org. Chem. 2011, 
1682-1694; i) D. P. Canterbury, G. C. Micalizio, Org. Lett. 2011, 13 2384-2387; j) O. Kubo, D. P. Canterbury, G. C. Micalizio, Org. Lett. 2012, 14, 5748-5751; k) E. K. Kemppainen, G. Sahoo, A. Valkonen, P. M. Pihko, Org. Lett. 2012, 14, 1086-1089; I) T. J. Donohoe, R. M. Lipiński, Angew. Chem. Int. Ed. 2013, 52, 2491-2494.

[6] For reviews see; a) T. Montagnon, D. Kalaitzakis, M. Triantafyllakis, M. Stratakis, G. Vassilikogiannakis, Chem. Commun. 2014, 50, 15480 15498; b) T. Montagnon, M. Tofi, G. Vassilikogiannakis, Acc. Chem. Res. 2008, 41, 1001-1011.

[7] a) M. Triantafyllakis, M. Tofi, T. Montagnon, A. Kouridaki, G. Vassilikogiannakis, Org. Lett. 2014, 16, 3150-3153; b) A. Kouridaki, T. Montagnon, M. Tofi, G. Vassilikogiannakis, Org. Lett. 2012, 14, 2374 2377; c) A. Kouridaki, T. Montagnon, D. Kalaitzakis, G. Vassilikogiannakis, Org. Biomol. Chem. 2013, 11, 537-541; d) D Noutsias, A. Kouridaki, G. Vassilikogiannakis, Org. Lett. 2011, 13 1166-1169; e) G. Vassilikogiannakis, I. Alexopoulou, M. Tofi, T Montagnon, Chem. Commun. 2011, 47, 259-261; f) M. Tofi, T. Montagnon, T. Georgiou, G. Vassilikogiannakis, Org. Biomol. Chem. 2007, 5, 772-777; g) T. Georgiou, M. Tofi, T. Montagnon, G. Vassilikogiannakis, Org. Lett. 2006, 8, 1945-1948.
[8] I. S. Young, P. S. Baran, Nature Chem. 2009, 1, 193-205.

[9] N. Z. Burns, P. S. Baran, R. W. Hoffmann, Angew. Chem. Int. Ed. 2009 48, 2854-2867.

[10] a) T. Newhouse, P. S. Baran, R. W. Hoffmann, Chem. Soc. Rev. 2009 38, 3010-3021; b) T. Gaich, P. S. Baran, J. Org. Chem. 2010, 75, 46574673.

[11] K. C. Nicolaou, T. Montagnon, P. S. Baran, Angew. Chem. Int. Ed. 2002, 41, 993-996.

[12] See Supporting Information for full details.

[13] a) G. C. M. Lee, E. T. Syage, D. A. Harcourt, J. M. Holmes, M. E. Garst, J. Org. Chem. 1991, 56, 7007-7014; b) W. E. Bauta, J. Booth, M. E. Bos, M. DeLuca, L. Diorazio, T. J. Donohoe, C. Frost, N. Magnus, P. Magnus, J. Mendoza, P. Pye, J. G. Tarrant, S. Thom, F. Ujjainwalla Tetrahedron 1996, 52, 14081-14102; c) P. Magnus, L. Diorazio, T. J. Donohoe, M. Giles, P. Pye, J. Tarrant, S. Thom, Tetrahedron 1996, 52, 14147-14176; d) F. Cermola, R. Sferruzza, M. R. lesce, Tetrahedron Lett. 2014, 55, 737-740. 
Layout 2:

\section{SHORT COMMUNICATION}

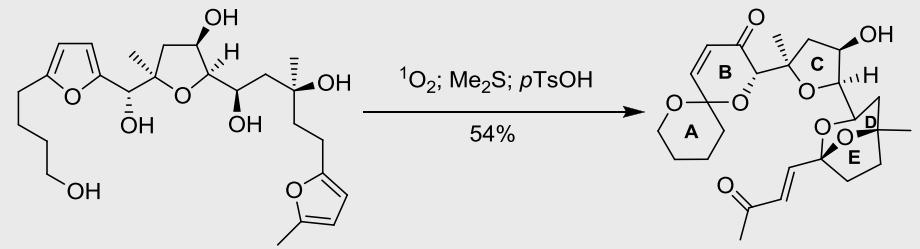

A singlet oxygen initiated cascade reaction sequence constructs both the $[6,6]$ spiroketal and the 2,8-dioxabicyclo[3.2.1]octane units found in pectenotoxins, starting from a simple difuran precursor, thus demonstrating the power of this nonclassical and sustainable oxidant in organic synthesis.

\section{Singlet Oxygen}

Antonia Kouridaki, Manolis Sofiadis,

Tamsyn Montagnon, Georgios

Vassilikogiannakis*

Page No. - Page No.

Pectenotoxin's ABCDE-ring system: A complex target to test the potential of singlet oxygen super cascades as tools for synthesis 